\title{
Paving the Road to Tobacco Free India - Covered and Uncovered
}

\author{
Dr. Mayur Nath T. Reddy ${ }^{1}$, Dr. Nisarga $\mathbf{M}^{2 *}$ \\ ${ }^{I}$ Professor \& Head, Department of Public Health Dentistry, Vydehi Institute of Dental Sciences \& Research \\ Centre, India \\ ${ }^{2}$ Post Graduate Student, Department of Public Health Dentistry, Vydehi Institute of Dental Sciences \& Research \\ Centre, India
}

*Corresponding Author: Dr. Nisarga M, Post Graduate Student, Department of Public Health Dentistry, Vydehi Institute of Dental Sciences \& Research Centre, India, Email: nisu2012@gmail.com

\begin{abstract}
According to the recently concluded (GATS-India 2016-2017), tobacco use is a major public health challenge in India, with 267 million adults consuming tobacco in different forms. Besides enacting comprehensive tobacco control legislation (COTPA, 2003), India was among the first few countries to ratify WHO the Framework Convention on Tobacco Control (WHO FCTC) in 2004. The National Tobacco Control Programme was piloted during the 11th Five Year Plan which is under implementation in 42 districts of 21 states in the country. By continuing to make tobacco control a top priority through strengthening the existing laws, we can build on our success and create a tobacco-free country.
\end{abstract}

Keywords: Paving, Tobacco free India, Covered.

\section{INTRODUCTION}

Tobacco kills half of its users, with smoking and smokeless tobacco killing nearly 6 million people worldwide. Every 6 seconds in each year, one death is said to be reported, according to the World Health Organization (WHO). [1]

Tobacco use is the leading single preventable cause of deaths worldwide. Each year an estimated 7 million deaths are attributed to the use of tobacco. On an average, tobacco users lose 15 years of life. Mortality due to tobacco in India is estimated at upwards of 1.3 million. [2]

Tobacco was introduced in India by Portuguese barely 400 years ago during the Mughal era. India is the second largest producer of tobacco in the world after China. India is also the second largest consumer of tobacco in the world, second only to China. [3]

According to Global Adult Tobacco Survey 2016, (GATS- INDIA) $19.0 \%$ of men, $2.0 \%$ of women and $10.7 \%$ (99.5 million) of all adults currently smoke tobacco. $29.6 \%$ of men, $12.8 \%$ of women and $21.4 \%$ (199.4 million) of all adults currently use smokeless tobacco. $42.4 \%$ of men, $14.2 \%$ of women and $28.6 \%$ (266.8 million) of all adults currently use tobacco. (smoked and/or smokeless tobacco). [4]

Legislation is recognized as the critical driver for meaningful progress in tobacco control. The
WHO framework convention on tobacco control (WHO FCTC) is a global public health treaty developed as a global response to the globalization of the tobacco epidemic, which aims at reducing the burden of disease and death caused by tobacco.

The WHO has established the MPOWER package to help countries comply with the WHO FCTC. This is a package encompassing six most important and effective tobacco control policies:

Monitoring tobacco use and prevention policies, Protecting people from tobacco smoke,

Offering help to people to quit tobacco use,

Warning everyone about the dangers of tobacco,

Enforcing ban on tobacco advertising, promotion and sponsorship

Raising taxes on tobacco. [5]

India has played a leadership role in global tobacco control. With the growing evidence of harmful and hazardous effects of tobacco, the Government of India enacted various legislations and comprehensive tobacco control measures. [3]

India's first national level anti-tobacco legislation was the cigarettes act of 1975, which mandated health warnings on cigarette packets and on cigarette advertisements. This act 
prescribed all packages to carry the warning "cigarette smoking is injurious to health" in the same language used in the branding on the package. [6]

The Act also contained specific restrictions for trading and commercialization practices regarding the production, supply, and distribution of tobacco. The Act set penalties, including the confiscation of tobacco in the event of its provisions being breached. However, the Act had major limitations as it did not include non-cigarette tobacco products, such as beedis, gutka, cigars, and cheroots. [7]

Smoking was included in the definition of air pollution by Prevention and Control of Pollution Act of 1981 and the Motor Vehicles Act of 1988 made it illegal to smoke or spit in a public vehicle. The Indian Government, in 1990, under the provision of the "Prevention of Food Adulteration Act (1955)" made mandatory to prescribe health warnings stating chewing of tobacco to be injurious to health. [8]

The Central Government, in December 1991 amended the Cinematograph Act, 1952, to ban scenes that endorse or promote the consumption of tobacco in any form. [9]

In 1992, the Central Government banned the sale of toothpastes and tooth powders containing tobacco under the "Drugs and Cosmetics Act" of 1940. [10]

The Cable Televisions Networks Amendment Act of 2000 prohibited the transmission of tobacco and liquor advertisements on cable television across the country and introduced penalties of imprisonment or fines for offenders. [11]

The Government enacted the Cigarettes and Other Tobacco Products (Prohibition of Advertisement and Regulation of Trade and Commerce, Production, Supply and Distribution) Act (COTPA), in 2003.

The provisions under the act included prohibition of smoking in public places, prohibition of advertisements of tobacco products, prohibition on sale of tobacco products to and by minors (persons below 18 years), ban on sale of tobacco products within 100 yards of all educational institutions and mandatory display of pictorial health warnings on tobacco products packages.

The law also mandates testing all tobacco products for their tar and nicotine content. Although the rules pertaining to various provisions under the law were notified during 2004 to 2006, there were many legal challenges which the Government had to face in view of the tobacco industry countering most of these rules in the court of law. [12]

Revised Smoke-free rules came into effect from 2nd October, 2008. The ban on smoking in public places, which included workplaces also, was a remarkable achievement in terms of political will and national commitment. Subsequently the law pertaining to pictorial warnings on tobacco products packages was implemented with effect from 31st May 2009. [13]

Ministry of Health and Family Welfare (MOHFW), in partnership with the WHO and the International Telecommunication Union (ITU), has started another innovative initiative by utilizing mobile technology for tobacco cessation. The WHO- ITU's "Be Healthy Be Mobile" initiative aims to reach out to tobacco users of all categories who want to quit tobacco use and support them toward successful quitting through constant text messaging on mobile phones. The initiative is fully supported by the Government of India (GOI). GOI had also introduced toll-free number (1800 11 2356/01122901701) to help for quitting tobacco and helpline 1800-110-456 for reporting of any COTPA violations. [1]

\section{The National Tobacco Control PROGRAMME (NTCP)}

The National Tobacco Control Programme (NTCP) was launched by MoHFW Government of India in 2007-08. The NTCP is presently under implementation in 21 states covering 42 districts (2 districts per state). It was launched during the 11th fiveyear plan, with the following objectives:

To bring about greater awareness about the harmful effects of tobacco use and about the Tobacco Control Laws.

To facilitate effective implementation of the Tobacco Control Laws [14]

\subsection{WHO Tobacco Free Initiative in India}

The Framework Convention on Tobacco Control (FCTC) was adopted by the World Health Assembly of the WHO at its 56th session in May 2003. India ratified the convention on 5th February 2004 and commenced enforcement of the national tobacco control law in May 2004.

Thirteen tobacco cessation clinics were set up in 12 states in our country during 2001-02 in 
diverse settings such as cancer treatment hospitals, psychiatric hospitals, medical colleges, non- Government organizations and community settings to help users to quit tobacco use. [15]

This network of Tobacco Cessation Clinics was further expanded in 2005 to cover five new clinics in Regional Cancer Centers (RCCs) in 5 states of which two centers were in the NorthEastern States of Mizoram and Assam, having high prevalence of tobacco use.

Tobacco cessation is one of the important links of tobacco control as it helps current users to quit tobacco use in a scientific manner. Article 14 of the WHO Framework Convention on Tobacco Control (FCTC) also requires countries to take effective measures to promote cessation of tobacco use and adequate treatment for tobacco dependence. [3]

The Dental Council of India (DCI) has directed 310 dental colleges across the country to set-up Tobacco Cessation Centres (TCCs) with a vision to help build the capacity of aspiring dental students and to help tobacco users quit it.

The need for such centres has been felt lately in view of rising oral cancer cases in India. Presently, Institute of Behavioural, Allied Sciences (IHBAS), Vallabhbhai Patel Chest Institute (VPCI) and Ram Manohar Lohia Hospital have three TCC centres in Delhi. This program is actively targeted at younger persons using tobacco, women users, rural populations and the economically underprivileged people. [16]

\subsection{The Tobacco Intervention Initiative}

The Tobacco Intervention Initiative (TII) is a professionally-led "call to action" programme to eradicate tobacco addiction while striving for a 'tobacco free India' and thus improving the oral health of Indians by the year 2020.TII aims to establish a broad alliance of key influencers and policy makers from research, education, clinical practice, public health, government and industry, partnering for a common goal --behavioral and lifestyle changes for a healthy India. The mission of TII is

- Making tobacco intervention accessible to all by establishing a chain of TCC Centres.

- Creating awareness and knowledge dissemination.

- Fostering commitment to tobacco cessation by training dental professionals.

- Creating a workforce of talented and skilled professionals.
- Developing multi-disciplinary approach in scientific and research related activities for tobacco intervention.

- Promoting timely transfer of research knowledge and its health implications to the public, dental professionals and policymakers. [17]

\subsection{WHO Bloomberg Initiative Work in India}

\subsubsection{Surveillance and Monitoring}

WHO supports the Government of India in identifying specific strategies for use of evidence in tobacco control policies and programmes, and in implementing effective MPOWER policies to protect health and combat the tobacco epidemic.

\subsubsection{Tobacco Control Policy and Legislation}

India has adopted new packaging and labelling provisions, establishing the components (i.e., content, size, rotation, etc.) of the health warnings, addressing the language(s) in which the health warnings must appear, as well as the location of the health warning. WHO has provided technical support for development and field-testing of the warning messages.

In October 2014, the average size of health warnings on all tobacco packages has been increased from $40 \%$ on one side of the pack to $85 \%$ on both sides of the pack. As the date for implementation was been delayed, WHO encouraged India to implement this important public health measure. This provision has come into force from April 2016.

\subsubsection{Capacity Building}

WHO has provided support for the National Tobacco Control Programme by building human resource capacity through training and hiring 18 tobacco control consultants (15 state consultants and three national consultants). These consultants have now been absorbed by the Ministry of Health and Family Welfare as part of its staff to implement the national tobacco control programme.

WHO Country Office for India, in collaboration with the MOHFW, has organized consultations on: economics of tobacco; illicit trade of tobacco products; curbing smokeless tobacco usage. It has also conducted workshops for law enforcers, senior police officials, state tobacco control officers and NGOs working in tobacco control. 
On 28 May 2013, WHO and the MOHFW released the "Guidelines for Law Enforcers, 2013" for effective implementation of tobacco control laws. These guidelines were developed with technical assistance and support from WHO and include a compilation of the latest rules and enforcement procedures for various provisions of the law.

A WHO-Johns Hopkins Bloomberg School of Public Health supported study to evaluate the impact of the gutka ban in key states of India was released at the National Conference on Tobacco or Health in Mumbai on 16 December 2014. It received a very high level of media coverage, with a large number of daily newspapers covering the outcomes.

On 29 May 2015, a national consultation on the illicit trade of tobacco products was organized by WHO, the Ministry of Health and Family Welfare, and the Ministry of Finance. It was attended by 120 officials and stakeholders from government and multiple sectors both national and state level.

On 23-24 June 2015 in New Delhi, WHO, in collaboration with the MOHFW, organized a National Workshop on the Collaborative Framework for National Programmes on Tuberculosis, Tobacco and Diabetes. The workshop provided a platform to develop joint implementation strategies to address comorbidities of tuberculosis and noncommunicable diseases, with a focus on diabetes and tobacco. [18]

\subsection{Smoke free Cities and Districts in India}

2007 - Chandigarh declared as the first smoke free city.

2007 - Kottayam in Kerala declared as the second smoke free city.

2007 - Shimla in Himachal Pradesh declared as the third smoke free city.

2010 - Sikkim declared the first smoke free state.

2014 - Himachal Pradesh became the second smoke free state.

2014 - Gariphema village in Nagaland declared the first tobacco-free village.

2016 - Kohima in Nagaland declared the fourth smoke free city. [19]

\section{Challenges AND OPPORTUNiTIES}

As the only country where single cigarettes can be bought, India needs to adopt a more holistic and coercive approach to fight the problems of tobacco. Not only the government, but all responsible citizens will need to support the fight against this global epidemic.

The current literacy rate in India is $74.04 \%$ [20] and hence the statutory warnings can only be read by those who are literate and is not impactful to the consumers who are illiterate. Acknowledging the lower literacy rate of the Indian population in rural areas government has notified $85 \%$ pictorial health warnings for mandatory display on both sides of the packet of cigarettes, beedis and chewing tobacco with effect from September 1, 2018.

On a positive note, 'The Cigarette Package Health Warnings: International Status Report' was released recently by the Canadian Cancer Society which documents global progress on plain packaging. It has ranked 206 countries and territories on the size of their health warnings on cigarette packages, and lists countries and territories that require graphic picture warnings. India has been ranked fifth in the listing of countries that have pictorial health warning on tobacco products, with experts here quick to add that the country is making tremendous progress towards creating public awareness on the health hazards of tobacco abuse. India, meanwhile, is the only SAARC country to have a Quit-Line number on tobacco products and the fourth in Asia after Thailand, Malaysia and Singapore.

Current written statutory warnings are printed predominantly only in English or English and Hindi (India's National Language). In many states in India, the majority of people only knows the local dialect and cannot read or write in either English or Hindi. [21]

It is an important barrier for those who are able to read local language only. In spite of WHO Bloomberg Initiative's on importance of addressing the languages in which health languages must appear, this is a major loophole in the existing laws which fails to identify and understand the local needs for the successful implementation.

Another major challenge ahead is the sale of single cigarettes. The theory behind outlawing the sale of single cigarettes is that selling them one at a time would slowly, subtly addict young people and others who might purchase a single cigarette and get hooked, when they would otherwise have avoided smoking entirely. Availability of cigarettes without any hassle makes it simpler for the smokers to sneak-in a stick at any point of the day. Also, the fact that a 
single stick is far more affordable than the whole pack makes it an attractive offer for the youngsters who manage to puff a smoke easily in a nearby pan-shop. In fact, the government of India had also come up with a proposal to support the prohibition on sale of unpacked cigarettes. Many states like Jammu and Kashmir and Himachal Pradesh do not allow the trading of single sticks. But Union Ministry of Health and Welfare holds the responsibility to concentrate on the areas of policies making and implementation on ban on sale of loose cigarettes. The Framework convention for Tobacco Control (FCTC) states that the sale of single cigarettes should be prohibited, presumably because it increases affordability and accessibility of tobacco for minors. The information from the database of the World Health Organization indicates that 97 countries have already adopted Section 16 of the WHO FCTC on prohibition selling a single cigarette and small packs of cigarette (sale of cigarettes individually or in small packets prohibited. [22]

In February 2014 Assam became the first state that went on to ban consumption of all form of smokeless tobacco by a law. Even pan masala which contain tobacco and nicotine are banned in Assam. Not just that Assam has also banned manufacture, advertisement, trade, storage, distribution and sale of smokeless tobacco products.

India is a major stakeholder in global tobacco control efforts and has always played a leadership role on various forums to bring the challenge posed by tobacco to the forefront. The country has taken many initiatives for tobacco control including legislative measures, ratification of the WHO FCTC and implementation of the National Tobacco Control Programme. The Indian anti-tobacco law is reasonably strong to comply with most of the provisions in the WHO FCTC. The Government is committed to face the challenge posed by high prevalence of tobacco use in the country and has tried mainstreaming tobacco control by integrating it into the ongoing national health programmes and National Rural Health Mission.

One of the areas needing attention is tobacco taxation. Taxation as a tool for price policy is at a very low level and even the low level of taxes are not effectively collected for all tobacco products except perhaps for cigarettes, rendering tobacco products quite inexpensive and affordable even by school children through their pocket money. [3]

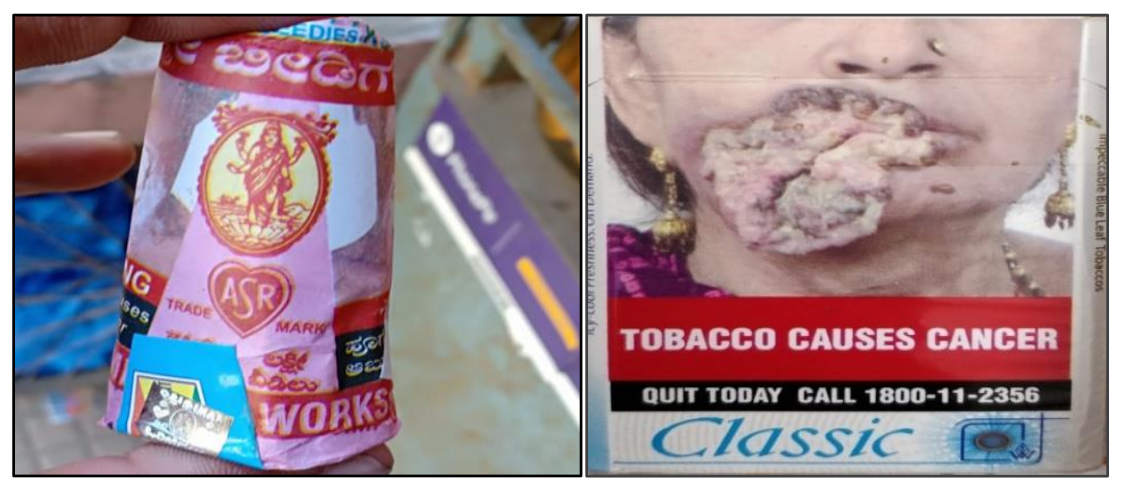

Figure1. Sample picture showing the percentage of pictorial warning in cigarette and beedi

The pictorial warning here on a beedi as well as cigarette catches our attention. In a country like India, where the production of beedis is much more compared to cigarettes, the consumer goes unnoticed with the pictorial warning present on the same. Rural population tend to continue with habit of consumption of tobacco in any other form without knowing the ill effects. This has to be addressed in terms of lobbying equally in terms of creating awareness among the public for all the tobacco products.

\section{CONClusion}

The Government of India has enacted and implemented various tobacco control policies at national and sub national level. But India needs to adopt a more holistic and coercive approach to fight the problems of tobacco. Effective tobacco control is possible by balanced implementation of demand and supply reduction strategies by the Government and inter-sectoral coordination involving stakeholder departments and ministries. Identifying the loop holes, interventions at various levels addressing these loop holes, effective monitoring, surveillance of the ongoing national programmes and strengthening the existing laws would help us achieve 'tobacco free country'. 


\section{REFERENCES}

[1] Saha I, Paul B. War against tobacco: Where do we stand? Indian J Public Health 2018;62:55-7.

[2] Tata Institute of Social Sciences (TISS), Mumbai and Ministry of Health and Family Welfare, Government of India. Global Adult Tobacco Survey GATS 2 India 2016-17.

[3] Kaur J, Jain DC. Tobacco Control Policies in India: Implementation and Challenges. Indian J Public Health 2011;55:220-7.

[4] Global Adult Tobacco Survey Fact sheet, INDIA 2016 - 2017 available at https://www.who.int/tobacco/surveillance/surve y/gats/GATS_India_2016-17_FactSheet.pdf accessed on 22/02/19.

[5] Mishra GA, Pimple SA, Shastri SS. An overview of the tobacco problem in India. Indian J Med PaediatrOncol 2012;33: 139-45.

[6] Government of India. The Cigarettes Act (Regulation of Production, Supply and Distribution) 1975.

[7] Mehrotra R, Mehrotra V, Jandoo T. Tobacco control legislation in India: Past and present. Indian J Cancer 2010;47 Suppl 1:75-80.

[8] Government of India. Prevention of Food Adulteration Act (PFA) (Amendment) 1990.

[9] Government of India. Cinematograph Act, 1952.

[10] Government of India. Drugs and Cosmetics Act 1940 (Amendment) 1992.

[11] Government of India. The Cable Television Networks (Amendment) Act 2000.

[12] The Cigarettes and Other Tobacco Products (Prohibition of Advertisement and regulation of Trade and Commerce, production, Supply and
Distribution) Act, 2003; An Act enacted by the Parliament of Republic of India by notification in the Official Gazette.

[13] Revised Smoke free Rules. Notification in the Official Gazette GSR 417 (E) dated 30th May, 2008.

[14] Government of India. National Tobacco Control Programme, 2007-08. Available from: http://www.mohfw.nic.in accessed on 20/03/19

[15] Sebastian ST, Johnson T. Tobacco Control Initiatives in India: An Overview. Int $\mathrm{J} \mathrm{Adv}$ Health Sci 2015;1(10):17-20.

[16] Tobacco cessation centers in Dental colleges available at www.dciindia.gov.inaccessed on 20/03/19

[17] The Tobacco Intervention Initiative available at www.tii.org accessed on 20/03/19

[18] WHO Bloomberg Initiative available at https://www.who.int/tobacco/about/partners/ bloomberg/ind/en/ accessed on 22/03/19

[19] India's Action plan for tobacco free states available from https://www.oneindia.com/ feature/india-s-action-plan-tobacco-free-states2097898.html accessed on 21/03/19

[20] The literacy rate of India available at http://niti.gov.in accessed on 20/03/19

[21] Ramachandra SS, Ramachandra SS. Antitobacco Messages on Tobacco Products in India: Do They Really Hit the Mark? Indian J Oral Health Res 2015;1:1-3.

[22] Countries around the world ban the sale of single cigarettes aiming to reduce cigarette demand by adolescents Press Release: Tobacco Control Research and Knowledge available at http://www.trc.or.th/en/accessed on 21/03/19

Citation: Mayur Nath T. Reddy, Nisarga M. Paving the Road to Tobacco Free India - Covered and Uncovered. ARC Journal of Cancer Science. 2019; 5(1):7-12. DOI:dx.doi.org/10.20431/2455-6009.0501002.

Copyright: () 2019 Authors. This is an open-access article distributed under the terms of the Creative Commons Attribution License, which permits unrestricted use, distribution, and reproduction in any medium, provided the original author and source are credited. 